\title{
Notes
}

\section{Characterization of Acetohydroxyacid Synthase Cofactors from Haemophilus influenza}

\author{
Vinayakumar Gedi, Bon-Sung Koo, ${ }^{\dagger}$ Dong-Eun Kim, ${ }^{\star}$ and Moon-Young Yoon ${ }^{*}$ \\ Department of Chemistry, College of Natural Sciences, and Research Institute of Natural Sciences, \\ Hanyang University, Seoul 133-791, Korea. ${ }^{*}$-mail: myyoon@hanyang.ac.kr \\ ${ }^{\dagger} F u n c t i o n a l$ Biomaterial Division, National Academy of Agricultural Science, RDA, Suwon 441-857, Korea \\ ॠDepartment of Bioscience and Biotechnology, WCU Program, Konkuk University, Seoul 143-701, Korea \\ Received August 23, 2010, Accepted September 16, 2010
}

Key Words: Acetohydroxyacid synthase, FAD reduction, Metal activation, ThDP-dependent enzyme

\begin{abstract}
Haemophilus influenzae (Hin) is a Gram-negative, rod-shaped bacterium usually involved in community-acquired respiratory tract infections, acute otitis media, acute sinusitis, exacerbation of chronic bronchitis, and childhood meningitis. ${ }^{1}$ Major respiratory pathogens are rapidly developing antibiotic resistance, creating both a serious problem of effectively managing respiratory tract infections and the need for new antibiotics. Previous studies of leucine and isoleucine-valine-leucine auxotrophs of M. tuberculosis ${ }^{\mathrm{H} 7 \mathrm{Rv}}{ }^{2}$ leucine auxotrophs of Mycobacterium bovis $\mathrm{BCG},{ }^{3}$ and the AHAS mutant of Burkholderia pseudo-
\end{abstract} mallei ${ }^{4}$ have shown that enzymes in branched chain amino acid (BCAA) synthesis pathways could be suitable targets for antimicrobial agents. In contrast, plants, algae, fungi, bacteria, and archaea synthesize these BCAAs, but animals do not.

The anabolic enzyme, acetohydroxyacid synthase (AHAS; EC 2.2.1.6) catalyzes the first step in the biosynthesis of the BCAAs valine, leucine, and isoleucine. AHAS, in common with several other enzymes that catalyze the decarboxylation of 2ketoacids, uses thiamine diphosphate (ThDP) as a cofactor and also requires a divalent metal ion to anchor ThDP in the active site. ${ }^{5}$ However, AHAS does not exhibit a high level of metal ion specificity for catalytic activity. Salmonella typhimurium AHASII was active in the presence of $\mathrm{Mn}^{2+}, \mathrm{Mg}^{2+}, \mathrm{Co}^{2+}, \mathrm{Ca}^{2+}$, $\mathrm{Ni}^{2+}, \mathrm{Cd}^{2+}, \mathrm{Zn}^{2+}$, or $\mathrm{Ba}^{2+}$. The three-dimensional structure of yeast AHAS reveals the location of several active-site features, including the position and conformation of the cofactors ThDP, $\mathrm{Mg}^{2+}$, and FAD. ${ }^{7}$ The reported crystal structures of AHAS assume that the metal ion observed in the structure is $\mathrm{Mg}^{2+}$, since it was added in high concentration $(>5 \mathrm{mM})$ to the crystallization buffer and to the protein during purification. ${ }^{7-8}$

In this study, metal ion activation of AHAS was performed with Hin-AHAS. Previously, we had purified recombinant HinAHAS and identified potent inhibitors. ${ }^{9}$ Cofactors and metal ion-free Hin-AHAS (apo-AHAS), prepared by exhaustive dialysis, showed a complete loss of residual activity. Subsequent addition of $1 \mathrm{mM} \mathrm{ThDP}$ and $10 \mathrm{mM} \mathrm{Mg}^{2+}$ (final concentrations) resulted in full reconstitution of activity $(100 \%)$. Besides $\mathrm{Mg}^{2+}$, the metal ions $\mathrm{Ca}^{2+}, \mathrm{Mn}^{2+}, \mathrm{Co}^{2+}, \mathrm{Ni}^{2+}, \mathrm{Cd}^{2+}, \mathrm{Cu}^{2+}$, and $\mathrm{Zn}^{2+}$ were tested as potential activators of apo-AHAS in the presence of $1 \mathrm{mM}$ ThDP, $10 \mu \mathrm{M}$ FAD and $100 \mathrm{mM}$ pyruvate. Only $\mathrm{Ca}^{2+}$,
$\mathrm{Mn}^{2+}$, and $\mathrm{Co}^{2+}$ were activators, providing $103 \%, 110 \%$, and $27 \%$ residual activity, respectively, whereas $\mathrm{Ni}^{2+}, \mathrm{Cd}^{2+}, \mathrm{Zn}^{2+}$, and $\mathrm{Ba}^{2+}$ with Hin-AHAS showed no activity. These results were not completely identical with $S$. typhimurium AHAS activation, ${ }^{6}$ in which significant activity was found with $\mathrm{Ni}^{2+}, \mathrm{Cd}^{2+}, \mathrm{Zn}^{2+}$, or $\mathrm{Ba}^{2+}$ activated AHAS. The $k_{\text {cat }}$ values of $\mathrm{Mg}^{2+}, \mathrm{Mn}^{2+}$, and $\mathrm{Ca}^{2+}$ activated Hin-AHAS were in a similar range $\left(4.48-6.68 \mathrm{~s}^{-1}\right)$, whereas, the $K_{\mathrm{c}}$ value for $\mathrm{Mn}^{2+}(0.37 \mathrm{mM})$ was significantly lower than the $K_{\mathrm{c}}$ values for $\mathrm{Mg}^{2+}$ and $\mathrm{Ca}^{2+}$ (Fig. 3 and Table 1). The $K_{\mathrm{c}}$ value for ThDP activation was about $9.1 \mu \mathrm{M}$ (Table 1 ), as determined by measuring the catalytic activity of the $10 \mathrm{mM}$ $\mathrm{Mg}^{2+}$-activated Hin-AHAS in the presence of $100 \mathrm{mM}$ pyruvate and $10 \mu \mathrm{M} F A D$.

AHAS has an essential requirement for FAD, which is unexpected, because the catalytic reaction does not involve oxidation or reduction. However, it was reported that the enzymebound FAD in AHAS is reduced in the course of catalysis in a side reaction. ${ }^{10}$ In this study, we found experimental evidence for the presence of FAD and its reduction in Hin-AHAS. Purified Hin-AHAS has a bright yellow appearance. Even with no additional FAD, maximum enzyme activity was observed, indicating that the purified Hin-AHAS contained sufficient endogenous FAD and a nearly saturated FAD binding site (data not shown). The UV-visible absorbance spectrum of Hin-AHAS showed two peaks at 378 and $451 \mathrm{~nm}$, which correspond to FAD (Figure 1). The molar concentration of bound FAD in $30.2 \mu \mathrm{M}$

Table 1. Metal ion and ThDP dependence of steady-state kinetic constants.

\begin{tabular}{crc}
\hline Cofactor & \multicolumn{1}{c}{$K_{\mathrm{c}}(\mathrm{mM})$} & $k_{\text {cat }}\left(\mathrm{s}^{-1}\right)$ \\
\hline $\mathrm{Mg}^{2+}$ & $0.74 \pm 0.02$ & 4.48 \\
$\mathrm{Mn}^{2+}$ & $0.37 \pm 0.01$ & 6.68 \\
$\mathrm{Ca}^{2+}$ & $1.06 \pm 0.04$ & 5.36 \\
$\mathrm{ThDP}$ & $0.0091 \pm 0.01$ & 4.5 \\
\hline
\end{tabular}

The metal ion dependence of the steady-state kinetic constants for AHAS catalysis was measured in the presence of $100 \mathrm{mM}$ pyruvate, $10 \mu \mathrm{M} \mathrm{FAD}$, and $1 \mathrm{mM} \mathrm{ThDP}$ at $\mathrm{pH}$ 7.5. The ThDP-dependent catalysis was performed with $10 \mathrm{mM} \mathrm{Mg}^{2+}$-activated AHAS in the presence of $100 \mathrm{mM}$ pyruvate and $10 \mu \mathrm{M} F A D$ with varied concentrations of ThDP. 


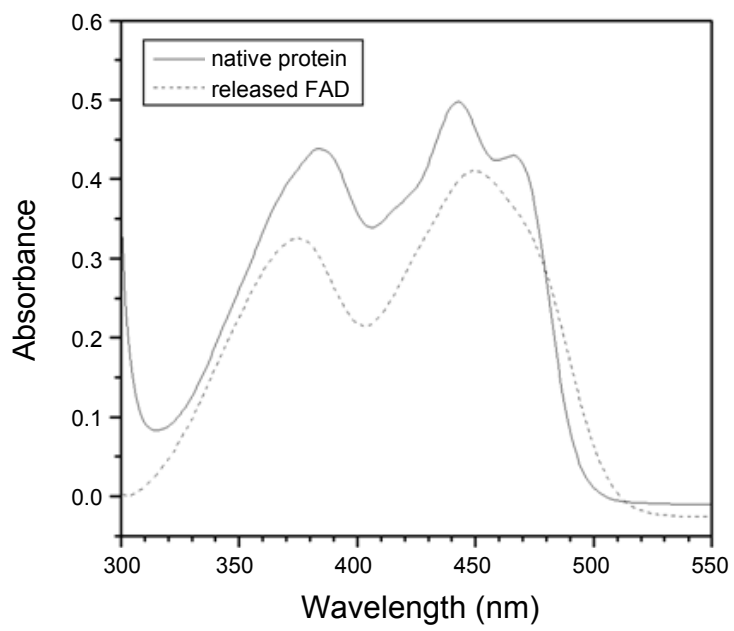

Figure 1. UV-vis absorbance spectra of native Hin-AHAS and released FAD. The released FAD was obtained by heat treatment, as described in the Methods section.

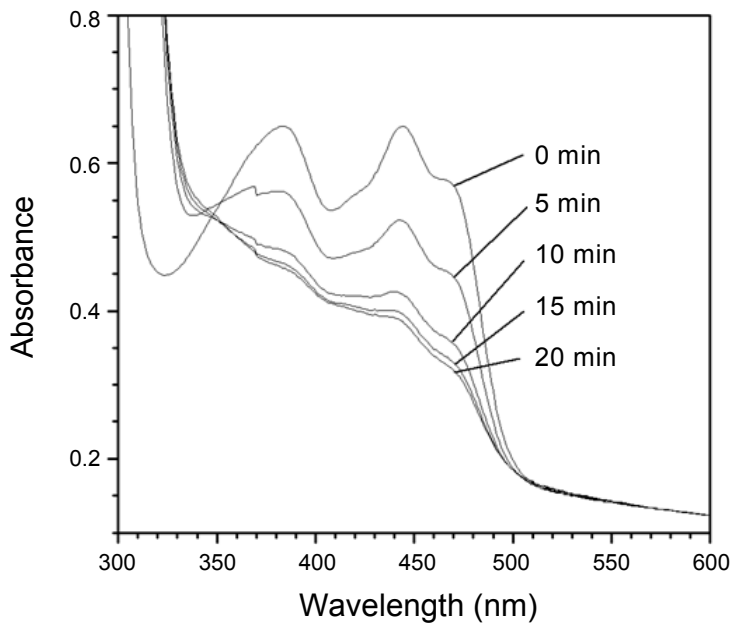

Figure 2. Time-dependent absorbance spectra of Hin-AHAS-bound FAD in the course of anaerobic reduction. The reaction was performed, as described in the Methods section. The spectra were recorded at 0 , 5,10 , and $20 \mathrm{~min}$ after adding pyruvate. of Hin-AHAS was determined to be $36.3 \mu \mathrm{M}$, based on the released FAD spectrum, indicating a 1:1 stoichiometry (Figure 1). Furthermore, the reduction of enzyme-bound FAD in Hin-AHAS in the course of catalysis was analyzed. The UV-visible absorbance spectrum of Hin-AHAS in $100 \mathrm{mM}$ potassium phosphate at $\mathrm{pH} 7.5$ and $1 \mathrm{mM}$ ThDP was recorded after addition of pyruvate at varied time intervals ( $0-20 \mathrm{~min})$. As shown (Fig. 2), a time-dependent reduction of FAD was found with the addition of pyruvate to the reaction mixture. This result provides further evidence that the FAD bound in AHAS was reduced completely within $20 \mathrm{~min}$.

By sequence alignment of Hin-AHAS with well-characterized AHASs from yeast, A. thaliana and E. coli, several key amino acid residues located at the active site or important for catalytic activity, respectively, were identified. The common step for all ThDP-dependent enzymes is the activation of the nucleophilic C2-atom, which occurs via deprotonation. A conserved glutamate residue (E139 in Yeast AHAS) donates a hy-

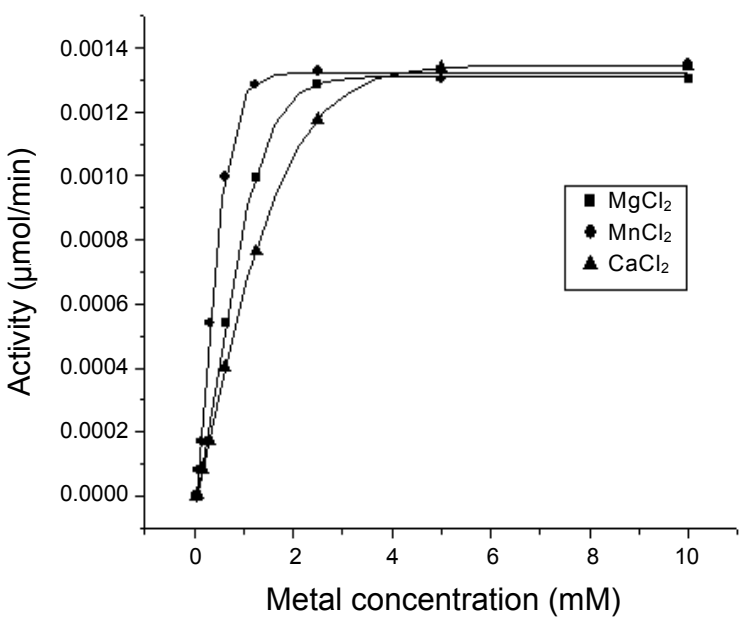

Figure 3. The activation of apo-AHAS in the presence of divalent metal ions, $\mathrm{Mg}^{2+}, \mathrm{Mn}^{2+}$, and $\mathrm{Ca}^{2+}$. The preparation of apo-AHAS and activation experiments were conducted, as described in the Methods section. The data were fit to a Hill equation, and values are reported in Table 1.

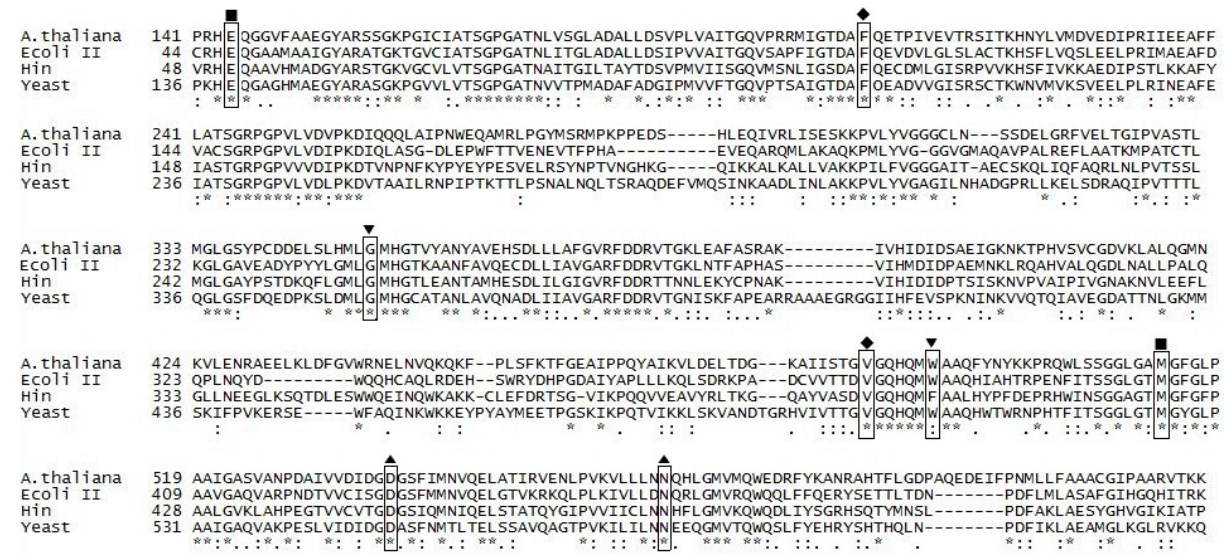

Figure 4. Sequence alignment of Hin-AHAS, as compared with the sequences of A. thaliana, E. coli, and yeast AHASs. Conserved AHAS amino acid residues, which were catalytically important, are shown in boxes with symbols. Each symbol represents a group of amino acids responsible for cofactor and substrate binding, respectively ( $\mathbf{\bullet}, \mathrm{ThDP} ; \boldsymbol{\Lambda}, \mathrm{Mg}^{2+} ; \mathbf{\nabla}, \mathrm{FAD}$ and $\bullet$, pyruvate binding). 
drogen bond to the $\mathrm{N} 1$ '-atom of the pyrimidine ring of ThDP, resulting in the activation of the $\mathrm{C}^{4}$ '-amino group, which is the acceptor of the attached C2-ThDP-proton. ${ }^{7}$ In the Hin-AHAS sequence, a strictly conserved glutamate residue, E51 (HinAHAS numbering), was identified and was predicted to be necessary for ThDP activation (Fig. 4). From several 3-D structures of ThDP-dependent enzymes, it was apparent that a divalent metal ion functions to anchor the ThDP molecule by coordinating two of the diphosphate oxygen atoms to the side chain oxygen atoms of the aspartate and the second asparagine residue of the ThDP-binding motif (D550 and N577 in Yeast AHAS). ${ }^{7}$ These two residues (D447 and N474, Hin-AHAS numbering) were also found to be conserved in Hin-AHAS (Fig. 4). A recent study of the pyruvate mechanism in E. coli AHAS indicated that a valine and a phenylalanine residue (V375 and F109 in E. coli AHAS) hydrophobically interact with the methyl substituent of pyruvate, ${ }^{11}$ and the alignment analysis also suggests conservation of these residues in all of the AHAS sequences (Fig. 4).

In conclusion, the present study characterizes the unique properties of AHAS cofactors. One molecule of FAD was found to be present in one molecule of Hin-AHAS, and bound FAD was reduced in a time-dependent manner with the addition of pyruvate. Further, Hin-AHAS was found be active in the presence of the varied divalent metal ions, $\mathrm{Mg}^{2+}, \mathrm{Mn}^{2+}$ and $\mathrm{Ca}^{2+}$. In the absence of a Hin-AHAS 3-D structure, we have compared various AHAS sequences by sequence alignment for which 3-D structures are available, and several conserved residues were identified in the Hin-AHAS sequence that are located at the active site or are important for catalytic activity.

\section{Experimental Section}

The molar ratio of FAD/Hin-AHAS. A reaction mixture containing $20 \mathrm{mM}$ Tris-HCl, $\mathrm{pH}$ 8.0, 0.15 M NaCl, $5 \mathrm{mM} \beta$-mercaptoethanol, $10 \%$ glycerol, and $30.2 \mu \mathrm{M}$ Hin-AHAS (final concentration) was prepared, and the absorbance spectrum between 300 - $550 \mathrm{~nm}$ was recorded on a Lambda25 UV-vis Spectrophotometer, PerkinElmer, USA. After this scan, the Hin-AHAS was denatured by boiling for $5 \mathrm{~min}$, cooled in an ice bath, and the protein precipitate was removed by centrifugation at $23,000 \times \mathrm{g}$ for $30 \mathrm{~min}$. The supernatant containing released FAD was collected, and the absorbance spectrum between $300-550 \mathrm{~nm}$ was recorded. The concentration of released FAD was determined from the absorbance at $450 \mathrm{~nm}\left(\mathrm{~A}_{450}=0.41\right)$, using the extinction coefficient for free FAD $\left(\varepsilon_{450}=11,300 \mathrm{M}^{-1} \mathrm{~cm}^{-1}\right)$.

FAD reduction during Hin-AHAS catalysis. Reduction of FAD was detected by recording the UV-visible spectra of HinAHAS between $300-600 \mathrm{~nm}$. Hin-AHAS (final concentration, $26.6 \mu \mathrm{M}$ ) was pre-incubated with $100 \mathrm{mM}$ potassium phos- phate, $\mathrm{pH} 7.5$, and $1 \mathrm{mM}$ ThDP at $37^{\circ} \mathrm{C}$ for $10 \mathrm{~min}$ in a quartz cuvette with a stopcock. The reaction was initiated by the addition of $100 \mathrm{mM}$ pyruvate, followed by purging the cuvette with argon gas. UV-visible spectra between 300 - $600 \mathrm{~nm}$ were obtained at $37{ }^{\circ} \mathrm{C}$ until FAD reduction was complete.

Metal ion and ThDP activation. Cofactor-free AHAS (apoAHAS) was prepared by dialysis against a buffer containing $100 \mathrm{mM}$ HEPES, $20 \mathrm{mM}$ EDTA, and $1 \mathrm{mM}$ DTT at $\mathrm{pH} 7.5$, followed by exhaustive dialysis against a buffer containing 100 mM HEPES and $1 \mathrm{mMDTT}$ at $\mathrm{pH} 7.5$ in order to remove EDTA. Metal ion activation assays were performed in $200 \mu \mathrm{L}$ reaction mixtures containing $100 \mathrm{mM}$ pyruvate, $1 \mathrm{mM} \mathrm{ThDP}$, and $10 \mu \mathrm{M}$ FAD, and varying concentrations of divalent metal ions in a buffer containing $100 \mathrm{mM}$ HEPES at $\mathrm{pH}$ 7.5. The reaction was initiated by the addition of $1 \mu \mathrm{g}$ of apo-AHAS. The enzyme assay was performed as described previously. ${ }^{12}$ The ThDP activation of apo-AHAS was performed, as described previously, with $\mathrm{Mg}^{2+}$ as the metal ion. ${ }^{13}$ All data points represent the average of at least two independent experiments.

Acknowledgments. This work was supported by grant of the Korea Research Foundation Grant funded by the Korean Government (KRF-2008-313-C00530). This work was supported by a grant (\#20080401034006) from the BioGreen21 Program, Rural Development Administration, the Republic of Korea.

\section{References}

1. Tristram, S.; Jacobs, M. R.; Appelbaum, P. C. Clin. Microbiol. Rev. 2007, 20, 368.

2. Guleria, I.; Teitelbaum, R.; McAdam, R. A.; Kalpana, G.; Jacobs, W. R., Jr.; Bloom, B. R. Nat. Med. 1996, 2, 334.

3. Bange, F. C.; Brown, A. M.; Jacobs, W. R., Jr. Infect. Immun. 1996, 64, 1794.

4. Atkins, T.; Prior, R. G.; Mack, K.; Russell, P.; Nelson, M.; Oyston, P. C. F.; Dougan, G.; Titball, R. W. Infect. Immun. 2002, 70, 5290.

5. McCourt, J. A.; Duggleby, R. G. Amino Acids 2006, 31, 173.

6. Schloss, J. V.; Van Dyk, D. E.; Vasta, J. F.; Kutny, R. M. Biochemistry 1985, 24, 4952.

7. Pang, S. S.; Duggleby, R. G.; Guddat, L. W. J. Mol. Biol. 2002, 317, 249.

8. McCourt, J. A.; Pang, S. S.; King-Scott, J.; Guddat, L. W.; Duggleby, R. G. PNAS. 2006, 103, 569.

9. Choi, K. J.; Noh, K. M.; Kim, D. E.; Ha, B. H.; Kim, E. E.; Yoon, M. Y. Arch. Biochem. Biophy. 2007, 466, 24.

10. Tittmann, K.; Schröder, K.; Golbik, R.; McCourt, J.; Kaplun, A.; Duggleby, R. G.; Barak, Z.; Chipman, D. M.; Hübner, G. Biochemistry 2004, 43, 8652 .

11. Steinmetz, A.; Vyazmensky, M.; Meyer, D.; Barak, Z.; Golbik, R.; Chipman, D. M.; Tittmann, K. Biochemistry 2010, 49, 5188.

12. Choi, K. J.; Pham, C. N.; Jung, H.; Han, S. H.; Choi, J. D.; Kim, J.; Yoon, M. Y. Bull. Korean Chem. Soc. 2007, 28, 7, 1109.

13. Kim, J.; Choi, J. D.; Kim, B. H.; Yoon, M. Y. Bull. Korean Chem. Soc. 2005, 26, 2, 260. 